\title{
Possibilities for the development of flexible planning and production control
}

\author{
Borislav Gordic \\ MIRAKO Co., Draskoviceva 57, Zagreb, University NORTH - University Center Varazdin, Department of Logistic, Varazdin, Croatia
}

\section{Email address:}

gordicb@yahoo.com

\section{To cite this article:}

Borislav Gordic. Possibilities for the Development of Flexible Planning and Production Control. Science Journal of Business and Management. Vol. 2, No. 5, 2014, pp. 143-152. doi: 10.11648/j.sjbm.20140205.15

\begin{abstract}
Based on the results of the research carried out in one production system an attempt is made to give an answer regarding the possibilities for the development of adaptive operational planning and production control, especially in terms of dynamics and mode of operation and linking of procurement, sales and production processes. Through selected criteria and measures and with adequate design of experiments and a simple simulation model, the influence factors have been defined, and by applying the analysis of variance the relative strength of their effect on the successfulness of operational planning and production control has been determined. The results obtained are a template for definition and development of the process of operational planning and production control and for the optimization of that process with the aim of meeting the maximum needs of the market through the realization in production, and achieving the highest possible success of a business enterprise, as a model of descrete periodical dynamic optimization.
\end{abstract}

Keywords: Successfulness of Operational Planning and Production Control, Influence Factors, Design of Experiments, Analysis of Variance, Flexible Planning and Control

\section{Introduction}

In the theory and practice of production and its management there is a large number of criteria and measures for the optimization of production programs and plans, and some of them are at the same time also indicators which speak of the efficiency and successfulness of production, that is, there are criteria and measures which individually provide insight into the results of a certain production process or its parts and contents.

However, there are two problems related to operational planning of production:

- the optimum is dominantly treated from the aspect of production itself and it diverges to a certain extent from the current events on the market

- a more precise insight into the influence of the direct operational planning and process control on the production itself, and vice versa, does not exist

As operational planning and control mostly affect the efficiency and successfulness of the direct production process, it is necessary to consider the criteria and measures according to which the successfulness and the efficiency of that organizational process, and not only of the production and its parts, would be evaluated.

The planning and process control is part of the organizational process in which the linking and coordination of particular organizational processes is carried out in the realization of the objectives set for the whole. Thereat, the process is treated as a set of logically connected and coordinated activities with the pertaining algorithms, input and output data.

As the results of the production process are mostly a consequence of the manner and efficiency of management and realization of the operational planning and process control, the obtained results and assessments of the efficiency of production need to be evaluations of the successfulness of operational planning and control at the same time.

The criteria that have been used in this research are presented in detail in the article entitled "Doprinos određivanju kriterija i mjerila za ocjenjivanje operativnog planiranja i praćenja proizvodnje" (A Contribution to the Determination of Criteria and Measures for Evaluating Operational Planning and Production Control) by Borislav Gordić published in the journal Tehnički vjesnik, Vol. 18, issue $1 / 2011$, pp. 109-115 [18]. This paper summarizes the employed criteria and measures. 


\section{Problem Definition}

Numerous writings, $[1,2,3,4,5,6,7]$, especially the ones from the domain of production economics, as well as everyday practice, use the following standard indicators to measure the business success of production:

- economy $=$ a ratio of cash return on capital invested

- productivity $=$ a ratio of output of goods and invested work hours

- profitability $=$ a ratio of profit and invested capital

The above mentioned indicators assess the business success of production. However, they do not tell us to which extent they are influenced by the acting influence factors of operational planning and control, as well as production itself.

The other problem occurs in practice, in almost all the production systems, when due to more or less dynamic changes on the market, there is a need to modify and amend the operational production plans $[8,9,10,11,12,14]$.

From the market aspect, meeting the market's demands is preferred, while the production system strives to realize such plans that enable the optimum results according to previously selected criteria and measures.

It may be basically concluded that, not only due to a certain number of disorders in the process of realization of production, but also due to the need for meeting the market's demands to the greatest and highest quality extent, in most cases the optimum planned results cannot be expected but only strived for.

It is possible to come closer to such planned results by improved management of the production system by virtue of an improved operational planning and process control and if the market provides input data that are precise and obtained in due time $[13,15,16,17]$.

Operational planning and production control is a process that connects the production and the market which is selfexplanatory for the importance of the process. Not only should it be well organized and managed but also adequately monitored and evaluated.

\section{Criteria and Measures}

The aim of this paper is to evaluate the process of operational planning and control, primarily the production process, as described and defined by the QUALITYDEADLINES-COSTS trinomial. The success of the planning and control process should be determined according to the criteria and measures that would describe each component of the above stated trinomial.

Hereupon, three criteria are suggested here for the evaluation of the success of the operational planning and production control. These were chosen based on their applicability in numerous segments of life and work and because they can be synthetically connected into a consolidated criterion for evaluating success:

1. The level of realization on the market in relation to the operational plans and realization of production SENSITIVITY OF PLANNING AND CONTROL $-U_{1}$
2. Level of meeting the delivery deadlines - MEETING THE DEADLINES $-U_{2}$

3. Level of participation of all the stock in relation to the realization on the market and expenditure in the production STOCK MANAGEMENT EFFICIENCY $-U_{3}$

For all the above criteria, the measures are dimensionless and stated in percentages (\%) which ensures that various production processes, that is, organizational systems, can be compared regardless of their size and content of work.

For the overall, synthetic evaluation of the success of operational planning and control, the notion SUCCESS OF PLANNING - $\mathrm{U}$ is chosen and it represents a group of individual criteria chosen according to an adequate algorithm.

The measure of the achieved level of sensitivity of the planning and control $U_{1}$ will be according to the expression (1) the product of the variation level $\left(1-\sigma_{\bar{x}} / \bar{x}\right)$ and the accuracy level $(1-\Delta \bar{x})$

$$
U_{1}=\left(1-\frac{\sigma_{\bar{x}}}{\bar{x}}\right) \cdot(1-\Delta \bar{x})
$$

where: $\bar{x}$ - mean value of the ratio between the annual and monthly plan and the realization of production in relation to the realization of the product on the market

$\sigma_{\bar{x}}$ - standard mean value deviation of the observed ratio $\bar{x}$

$\Delta \bar{x}$ - error in the planning $(\Delta \bar{x}=\mathrm{I} 1-\bar{x} 1)$

Meeting the set deadlines is an aim and an obligation of every system in its functioning and thereat each system strives to meet as many deadlines as possible, and in case of a delay, to make it as short as possible so that the consequences of the delay are not too expensive.

Therefore, we can say that the measure of the achieved level of deadlines met $U_{2}$ will be according to the expression (2) a product of the share of deadlines met $\left(\left(\mathrm{R}-R_{Z}\right) / \mathrm{R}\right)$ and the level of delay $\left(1-\bar{x}_{z} / \bar{x}_{D I}\right)$

$$
U_{2}=\left(\left(\mathrm{R}-R_{z}\right) / \mathrm{R}\right) \cdot\left(1-\bar{x}_{z} / \bar{x}_{D I}\right)
$$

where: $\mathrm{R}$ - total annual number of set deadlines (delivery days)

$R_{z}$ - the annual number of unmet delivery deadlines (with a delay)

$\bar{x}_{z}$ - average number of days of delay

$\bar{x}_{D I}\{0>$ - prosječan broj dana postavljen kao rok $<\} 0\{>-$ average number of days set as a delivery deadline

When choosing the criterion which might be the most prominent and sufficiently realistic in showing the efficiency of planning and control, hereupon the case of production system, it has been assessed that this should be efficient stock management.

Therefore, the ratio $O_{s}$ between the stock and raw material use in production and the ratio between the stock of finished products and delivered products $O_{p}$ has been taken here as a standard of efficiency, particularly, of the stock management efficiency $U_{3}$ as defined by the following expression

$$
U_{3}=\frac{1}{1 / 2 \cdot\left(O_{p}+O_{s}\right)}
$$

where: 


$$
\begin{gathered}
O_{p}=\frac{\sum \sum\left(\bar{z}_{p} / \bar{x}_{p}\right)_{i j}}{12 \cdot p} \\
O_{p}=\frac{\sum \sum\left(\bar{z}_{s} / \bar{x}_{u s}\right)_{i j}}{12 \cdot s}
\end{gathered}
$$

where: $\left(\bar{z}_{p}\right)_{i j}$ - average daily state of products stock $(\mathrm{j})$ in a certain month (i)

$\left(\bar{x}_{p}\right)_{i j^{-}}$quantity of the delivered products $(\mathrm{j})$ in a certain month (i)

$\left(\bar{z}_{S}\right)_{i j}$ - average daily state of raw materials stock $(\mathrm{j})$ in a certain month (i)

$\left(\bar{x}_{u s}\right)_{i j}$ - quantity of the used raw materials $(\mathrm{j})$ in a certain month (i)

According to expression (6), the evaluation of the planning and control of the observed process in the chosen system can be done according to the synthetic criteria $U$ - successfulness of planning and control.

$$
\mathrm{U}=U_{1} \cdot U_{2} \cdot U_{3}
$$

\section{Study of the State}

This study was conducted in a kitchenware factory, where the production process was analysed. The experience in organization and management design for several business systems was also employed.

Based on the research findings, including its processes of operational planning and production control, marketing, supply and production, an analysis of the influence factors has been made. On the basis of this analysis, the most influential factors that will be treated in the further work have been selected. They include the following:

Intensity of input data collection

Forms of product placement

Operational planning and production control methods

Frequency and duration of machine failures

Frequency and duration of human failures

For the second study of the state, study on a model has been selected, and for that purpose $2^{5}$ factorial experiment plan, with two levels of treatment of the selected influence factors, using a simple simulation program, has been used.

As the first level of each factor, its existing size, i.e. form has been taken, and as the second level, those sizes, i.e. forms that can be realistically and easily achieved as follows:

A1 - 2 data collections per week for a part of the process

A2 - 5 data collections per week for the process

B1 - placement of stocks, mostly for unknown customers $(59 \%)$

B2 - direct placement of stocks, mostly for unknown customers $(60 \%)$

$\mathrm{C} 1$ - static, periodical planning and control

C2 - flexible, more intensive planning and control

D1 - frequency and duration of equipment failure, the current one

D2 - frequency and duration of failures, for $1 / 3$ less than the current one

E1 - frequency and duration of human failures in the processes, the current one
E2 - frequency and duration of human failures, for $1 / 3$ less than the current one

The flexible operational planning and production control as a simpler and in practice easier applied type of dynamic planning and control implies a method of work where the plans of higher level - longer period, are updated - adjusted and supplemented with respect to the changes in the system and its environment after the expiry of the time period of the next lower operational plan.

The principle of flexible operational planning and production control is illustrated in Figure 1 where it can be seen that the first basic plan OP1 is being corrected after each particular correction time (Tk)o. Upon expiry of the time period of the basic plan, the correction of the higher plan VP1' is done and at the same time the basic plan for the next basic planning period is defined, etc.

For the needs of simulation, the data and relations that define the treated processes have been used, and for the needs of the utilized simulation program two transformations of the input sales data and one transformation for the input production materials have been made.

The simulation was actually run with 4 models that were 4 combinations of both levels of factors B and C. A total of 6 repetitions of each experiment were run. After that the results obtained per indicators for the selected criteria and measures $U_{1}, U_{2}$ and $U_{3}$, and the overall indicator $\mathrm{U}$ as the synthetic criterion according to expression (6), as shown in Table 1, were processed and sorted.

Comparison of the results obtained by recording the current state and those obtained by simulation in the experiment with all factors at the first level by $\mathrm{t}$-test has shown the reliability of the results obtained by simulation according to all criteria.

The obtained data were subjected to the analysis of variance for the results of the $2^{5}$ experiment according to all criteria, and the results according to the synthetic criterion Usucessfulness of planning and control are shown in Table 1.

From the relationship between variance of effects and variance of the remaining part Fcalc., the significance of the influence factors and interactions has been determined when Fcalc. $>$ Ftab. $=2.20$ for the probability $\alpha=0.01$ for higher value of $\mathrm{F}$, and thus according to the calculation values given in Table 1. the following influence factors and interactions have been determined by the rank:

factor $\mathrm{C}$ - operational planning and production control methods, very strong influence +VSSS

factor B - forms of product placement, very strong influence +VSSS

factor $\mathrm{E}-$ frequency and duration of human failure, strong influence + SSS

factor A - intensity of input data collection, very strong influence +VSSS

interaction $\mathrm{ABC}$, very strong influence -VSSS

factor D - frequency and duration of machine and euipment failure, significant influence $+\mathrm{SS}$

interaction $\mathrm{AB}$, significant influence $-\mathrm{SS}$

For the sake of additional analysis, evaluation, and 
improved insight in the effect of the previosly defined main influence factors C-operational planning and production control methods and B-forms of product placement, two more groups of $2^{4}$ experiments have been made. They were based on the results obtained according to the criterion Usuccessfulness of operational planning and production

I.

control, and they included the following:

Experiments UB - factor B - forms of product placement has been omitted

Experiments UAC - factor A - intensity of input data collection and $\mathrm{C}$-operational planning and production control methods has been condensed (unified)

II. III. (months)

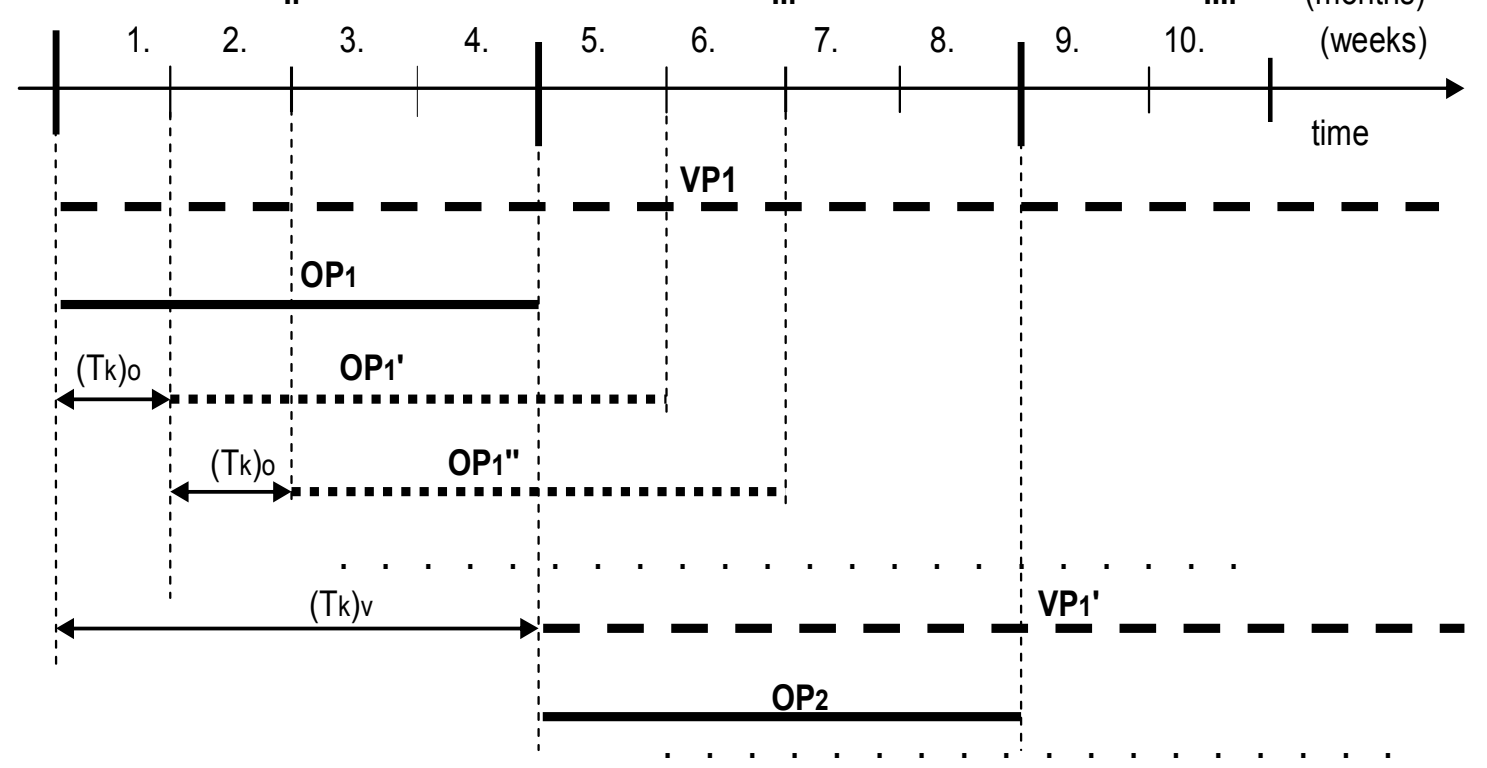

Figure 1. Schematic presentation of the principle of flexible operational planning and production control.

By omitting factor B from the treatment, Table 2, it can be seen that the impact of factor $\mathrm{C}$ is still very pronounced, that there is an even stronger effect of factor A, a very big impact of factor $\mathrm{E}$ and a strong influence of $\mathrm{AC}$ interaction, and pronounced impact of factor D. It can be also seen that the influence of $\mathrm{AC}$ interaction is positive whenever the variant of placement for stocks and not for the mainly known customers is in question.

According to the presentation in Table 3 it is evident that the interaction $\mathrm{AC}$ as a condensed factor (AC) has an even greater impact in all aspects than it was in previously performed experiments $2^{5}$. Impact of factor $E$ is also strong and $\mathrm{B}(\mathrm{AC})$ interaction is presented here with pronounced negative impact, which is logical.

In the model of flexible planning and control one of the main activities is continuous collection, sorting and processing of information related to changes in the environment and the system itself. Therefore, the condensation of that part of the factor A with the factor $\mathrm{C}$, or flexible planning and control, as well as condensed factor (AC) could be recommended.

\section{General Solution Proposal}

Since the influence factor "C-operational planning and production control methods" has proved to have the most significant effect on the sucessfulness of planning and control, an attempt has been made to find a relatively simple solution that can be easily applied in various economic and other systems. Such a general solution can be "flexible planning and control" presented in Figure 2.

As it is difficult to define exactly the basic planning period, here its 3 basic variants, defined according to the previously given parameters are proposed.

Additional factors that were also considered while defining the variants of the basic planning period are related to the financial-accounting and legal frameworks. Thus, based on the above considerations, the following variants of the basic planning period are proposed:

1. Longer basic planning period, in the duration of 6 months

- for the case of production by order, greater complexity, and a smaller number of deliveries

2. Medium basic planning period, in the duration of 3 months

- for the case of production by order, greater complexity, and a larger number of deliveries

- for the case of production by order, lower complexity, and a smaller number of deliveries

- for the case of stock production, greater complexity, and a smaller number of deliveries

- for the case of stock production, lower complexity and a larger number of deliveries

3. Shorter Basic Planning Period, in the Duration of 1 Month

- for the case of production by order, lower complexity, and a larger number of deliveries

- for the case of stock production, greater complerxity, and 
a larger number of deliveries

- for the case of stock production, lower complexity, and a smaller number of deliveries

According to the practical work experiences, the levels of plans and reports can be divided into groups with the framework time coverage, as follows:
1. Long-term plan and report - the highest planning period, covering more than 5 years

2. Medium-term plan and report - the third higher planning period, covering 3-5 years

3. Annual plan and report - the second higher planning period, covering 1 year

Table 1. Analysis of variance for synthetic criterion $U$ in $2{ }^{5} \times 6$ experiment

\begin{tabular}{|c|c|c|c|c|c|c|c|c|}
\hline \multicolumn{2}{|c|}{ Experiments U } & \multicolumn{6}{|c|}{ Obtained results (Yijklm)Pi in repetitions $\mathbf{P i}$} & \multirow{2}{*}{$\Sigma \mathrm{YPi}$} \\
\hline No. & Status & P1 & $\mathbf{P 2}$ & P3 & $\mathbf{P 4}$ & P5 & P6 & \\
\hline 1 & & 0,611 & 0,622 & 0,629 & 0,588 & 0,664 & 0,613 & 3,727 \\
\hline 2 & a & 0,671 & 0,700 & 0,679 & 0,625 & 0,599 & 0,607 & 3,881 \\
\hline 3 & $\mathrm{~b}$ & 0,667 & 0,653 & 0,644 & 0,709 & 0,740 & 0,663 & 4,076 \\
\hline 4 & $\mathrm{ab}$ & 0,776 & 0,812 & 0,704 & 0,745 & 0,760 & 0,847 & 4,644 \\
\hline 5 & $\mathrm{c}$ & 0,657 & 0,645 & 0,707 & 0,626 & 0,633 & 0,727 & 3,995 \\
\hline 6 & ac & 0,795 & 0,858 & 0,786 & 0,815 & 0,853 & 0,811 & 4,918 \\
\hline 7 & $\mathrm{bc}$ & 0,862 & 0,920 & 0,891 & 0,883 & 0,891 & 0,865 & 5,312 \\
\hline 8 & $a b c$ & 0,781 & 0,889 & 0,836 & 0,889 & 0,881 & 0,839 & 5,115 \\
\hline 9 & $\mathrm{~d}$ & 0,592 & 0,672 & 0,702 & 0,622 & 0,612 & 0,626 & 3,826 \\
\hline 10 & ad & 0,653 & 0,672 & 0,743 & 0,686 & 0,711 & 0,645 & 4,110 \\
\hline 11 & bd & 0,732 & 0,742 & 0,719 & 0,770 & 0,648 & 0,735 & 4,346 \\
\hline 12 & abd & 0,842 & 0,790 & 0,833 & 0,807 & 0,877 & 0,858 & 5,007 \\
\hline 13 & $\mathrm{~cd}$ & 0,716 & 0,716 & 0,811 & 0,702 & 0,744 & 0,761 & 4,450 \\
\hline 14 & acd & 0,809 & 0,932 & 0,925 & 0,857 & 0,898 & 0,893 & 5,314 \\
\hline 15 & bcd & 0,899 & 0,888 & 0,880 & 0,904 & 0,899 & 0,930 & 5,400 \\
\hline 16 & abcd & 0,875 & 0,817 & 0,925 & 0,912 & 0,806 & 0,893 & 5,228 \\
\hline 17 & $\mathrm{e}$ & 0,649 & 0,692 & 0,655 & 0,708 & 0,665 & 0,680 & 4,049 \\
\hline 18 & ae & 0,699 & 0,724 & 0,725 & 0,726 & 0,778 & 0,679 & 4,331 \\
\hline 19 & be & 0,737 & 0,766 & 0,767 & 0,755 & 0,736 & 0,815 & 4,576 \\
\hline 20 & abe & 0,940 & 0,833 & 0,869 & 0,873 & 0,815 & 0,918 & 5,248 \\
\hline 21 & ce & 0,760 & 0,770 & 0,753 & 0,797 & 0,738 & 0,787 & 4,605 \\
\hline 22 & ace & 0,913 & 0,908 & 0,915 & 0,945 & 0,925 & 0,907 & 5,513 \\
\hline 23 & bce & 0,921 & 0,922 & 0,966 & 0,909 & 0,955 & 1,038 & 5,711 \\
\hline 24 & abce & 0,909 & 0,890 & 0,984 & 0,952 & 0,925 & 0,874 & 5,534 \\
\hline 25 & de & 0,715 & 0,685 & 0,741 & 0,743 & 0,732 & 0,779 & 4,395 \\
\hline 26 & ade & 0,727 & 0,723 & 0,724 & 0,745 & 0,792 & 0,721 & 4,432 \\
\hline 27 & bde & 0,781 & 0,800 & 0,809 & 0,754 & 0,731 & 0,798 & 4,673 \\
\hline 28 & abde & 0,971 & 0,908 & 0,912 & 0,928 & 0,905 & 0,872 & 5,496 \\
\hline 29 & cde & 0,824 & 0,748 & 0,793 & 0,857 & 0,780 & 0,799 & 4,801 \\
\hline 30 & acde & 0,854 & 0,909 & 0,930 & 0,952 & 0,900 & 0,909 & 5,454 \\
\hline 31 & bcde & 0,901 & 0,950 & 0,990 & 0,965 & 0,955 & 0,966 & 5,727 \\
\hline 32 & abcde & 0,939 & 0,897 & 0,942 & 0,934 & 0,896 & 0,954 & 5,562 \\
\hline \multirow[t]{5}{*}{$\Sigma \mathrm{Y}^{2}$} & & 20,167 & 20,559 & 21,301 & 21,000 & 20,581 & 21,208 & \\
\hline & & & & & & & $\Sigma \mathrm{Y}$ & 153,456 \\
\hline & & \multicolumn{6}{|c|}{ Total sum of the square of deviation $\Sigma \mathrm{Q}=\Sigma \mathrm{Y}^{2}-(\Sigma \mathrm{Y})^{2}=$} & 2,167040 \\
\hline & & \multicolumn{6}{|c|}{ Corrected, explained sum of the square of deviation $\Sigma \mathrm{Qt}=$} & 1,964715 \\
\hline & & \multicolumn{6}{|c|}{ Unexplained residual - error $\mathrm{Qp}=\Sigma \mathrm{Q}-\Sigma \mathrm{Qt}=$} & 0,202325 \\
\hline
\end{tabular}


Table 1. Continued.

\begin{tabular}{|c|c|c|c|c|c|c|c|c|c|c|c|}
\hline \multirow{2}{*}{\multicolumn{2}{|c|}{ Experiments U }} & \multicolumn{5}{|c|}{ Treatment combination totals } & \multirow{3}{*}{ Divisor } & \multirow{3}{*}{$\begin{array}{l}\text { Effects } \\
E\end{array}$} & \multirow{3}{*}{$\begin{array}{l}\text { Variance } \\
(\delta e)^{2}\end{array}$} & \multirow{3}{*}{$\begin{array}{l}\text { Frač. }= \\
\delta \mathrm{e}^{2} / \delta \mathbf{o}^{2}\end{array}$} & \multirow{3}{*}{$\begin{array}{l}\text { Signif. \& } \\
\text { Rank }\end{array}$} \\
\hline & & \multirow{2}{*}{$\begin{array}{l}\mathbf{Y i}+\mathbf{Y i + 1} \\
\mathbf{Y i}+1-\mathbf{Y i}\end{array}$} & \multirow{2}{*}{$\begin{array}{l}(\mathbf{Y i}+\mathbf{Y i}+\mathbf{1})^{\prime} \\
(\mathbf{Y i}+\mathbf{1}-\mathbf{Y i})^{\prime}\end{array}$} & \multirow{2}{*}{$\frac{(\mathbf{Y i}+\mathbf{Y i}+1) "}{(\mathrm{Yi}+1-\mathrm{Yi})^{\prime \prime}}$} & \multirow{2}{*}{$\frac{(\mathbf{Y i}+\mathbf{Y i}+\mathbf{1})^{\prime \prime \prime}}{(\mathbf{Y i}+\mathbf{1}-\mathbf{Y i})^{\prime \prime \prime}}$} & \multirow{2}{*}{$\frac{(\mathbf{Y i}+\mathbf{Y i + 1})^{\prime \prime \prime}}{(\mathbf{Y i}+\mathbf{1}-\mathbf{Y i})^{\prime \prime \prime \prime}}$} & & & & & \\
\hline No. & Status & & & & & & & & & & \\
\hline 1 & & 7,608 & 16,328 & 35,668 & 73,349 & 153,456 & 192 & 0,79925 & & & \\
\hline 2 & a & 8,720 & 19,340 & 37,681 & 80,107 & 6,118 & 96 & 0,06373 & 0,194948 & 154,166 & $+\operatorname{VSSS}(4)$ \\
\hline 3 & $\mathrm{~b}$ & 8,913 & 17,289 & 39,567 & 3,085 & 9,854 & 96 & 0,10265 & 0,505736 & 399,940 & $+\operatorname{VSSS}(2)$ \\
\hline 4 & $a b$ & 10,427 & 20,392 & 40,540 & 3,033 & $-2,092$ & 96 & $-0,02179$ & 0,022794 & 18,026 & -SS (7) \\
\hline 5 & $\mathrm{c}$ & 7,936 & 18,204 & 1,448 & 4,907 & 11,822 & 96 & 0,12315 & 0,727915 & 575,640 & +VSSS (1) \\
\hline 6 & $\mathrm{ac}$ & 9,353 & 21,363 & 1,637 & 4,947 & $-0,844$ & 96 & $-0,00879$ & 0,003710 & 2,934 & $-\mathrm{S}(11)$ \\
\hline 7 & $\mathrm{bc}$ & 9,764 & 18,996 & 1,685 & $-1,365$ & $-0,776$ & 96 & $-0,00808$ & 0,003136 & 2,480 & $-\mathrm{S}(12)$ \\
\hline 8 & $a b c$ & 10,628 & 21,544 & 1,348 & $-0,727$ & $-6,026$ & 96 & $-0,06277$ & 0,189129 & 149,564 & -VSSS (5) \\
\hline 9 & d & 8,380 & 0,722 & 2,626 & 6,115 & 2,986 & 96 & 0,03110 & 0,046439 & 36,724 & $+\mathrm{SSS}(6)$ \\
\hline 10 & ad & 9,824 & 0,726 & 2,281 & 5,707 & $-0,148$ & 96 & $-0,00154$ & 0,000114 & 0,090 & \\
\hline 11 & $\mathrm{bd}$ & 10,118 & 0,945 & 2,571 & $-0,249$ & $-0,540$ & 96 & $-0,00563$ & 0,001519 & 1,201 & \\
\hline 12 & abd & 11,245 & 0,692 & 2,376 & $-0,595$ & 0,710 & 96 & 0,00740 & 0,002626 & 2,076 & \\
\hline 13 & $\mathrm{~cd}$ & 8,827 & 0,954 & $-0,706$ & $-0,151$ & $-0,520$ & 96 & $-0,00542$ & 0,001408 & 1,114 & \\
\hline 14 & acd & 10,169 & 0,731 & $-0,659$ & $-0,625$ & $-0,406$ & 96 & $-0,00423$ & 0,000859 & 0,679 & \\
\hline 15 & bcd & 10,255 & 0,860 & $-0,695$ & $-2,947$ & $-0,946$ & 96 & $-0,00985$ & 0,004661 & 3,686 & $-S(10)$ \\
\hline 16 & abcd & 11,289 & 0,488 & $-0,032$ & $-3,079$ & $-0,008$ & 96 & $-0,00008$ & 0,000000 & 0,000 & \\
\hline 17 & e & 0,154 & 1,112 & 3,012 & 2,013 & 6,758 & 96 & 0,07040 & 0,237868 & 188,107 & +VSSS (3) \\
\hline 18 & ae & 0,568 & 1,514 & 3,103 & 0,973 & $-0,052$ & 96 & $-0,00054$ & 0,000014 & 0,011 & \\
\hline 19 & be & 0,923 & 1,417 & 3,159 & 0,189 & 0,040 & 96 & 0,00042 & 0,000008 & 0,007 & \\
\hline 20 & abe & $-0,197$ & 0,864 & 2,548 & $-0,337$ & 0,638 & 96 & 0,00665 & 0,002120 & 1,677 & \\
\hline 21 & ce & 0,284 & 1,444 & 0,004 & $-0,345$ & $-0,408$ & 96 & $-0,00425$ & 0,000867 & 0,686 & \\
\hline 22 & ace & 0,661 & 1,127 & $-0,253$ & $-0,195$ & $-0,346$ & 96 & $-0,00360$ & 0,000624 & 0,493 & \\
\hline 23 & bce & 0,864 & 1,342 & $-0,223$ & 0,047 & $-0,474$ & 96 & $-0,00494$ & 0,001170 & 0,925 & \\
\hline 24 & abce & $-0,172$ & 1,034 & $-0,372$ & 0,663 & $-0,132$ & 96 & $-0,00137$ & 0,000091 & 0,072 & \\
\hline 25 & de & 0,282 & 0,414 & 0,402 & 0,091 & $-1,040$ & 96 & $-0,01083$ & 0,005633 & 4,455 & $-\mathrm{S}(8)$ \\
\hline 26 & ade & 0,672 & $-1,120$ & $-0,553$ & $-0,611$ & $-0,526$ & 96 & $-0,00548$ & 0,001441 & 1,140 & \\
\hline 27 & bde & 0,908 & 0,377 & $-0,317$ & $-0,257$ & 0,150 & 96 & 0,00156 & 0,000117 & 0,093 & \\
\hline 28 & abde & $-0,177$ & $-1,036$ & $-0,308$ & $-0,149$ & 0,616 & 96 & 0,00642 & 0,001976 & 1,563 & \\
\hline 29 & cde & 0,037 & 0,390 & $-1,534$ & $-0,955$ & $-0,702$ & 96 & $-0,00731$ & 0,002567 & 2,030 & \\
\hline 30 & acde & 0,823 & $-1,085$ & $-1,413$ & 0,009 & 0,108 & 96 & 0,00112 & 0,000061 & 0,048 & \\
\hline 31 & bcde & 0,653 & 0,786 & $-1,475$ & 0,121 & 0,964 & 96 & 0,01004 & 0,004840 & 3,828 & $+\mathrm{S}(9)$ \\
\hline 32 & abcde & $-0,165$ & $-0,818$ & $-1,604$ & $-0,129$ & $-0,250$ & 96 & $-0,00260$ & 0,000326 & 0,257 & \\
\hline \multicolumn{12}{|c|}{$\Sigma \mathrm{Y}^{2}$} \\
\hline & & & \multicolumn{7}{|c|}{ Degree of freedom of main interaction effects, with $n=5$ factors, Sst $=2^{n}-1=$} & 31 & \\
\hline & & & \multicolumn{7}{|c|}{ Total degree of freedom, with $r=6$ repetitions, $S s u=\left(2^{n} \times r\right)-1=$} & 191 & \\
\hline & & & \multicolumn{7}{|c|}{ Degree of freedom of residual - error, $\mathrm{Ssp}=\mathrm{Ssu}-\mathrm{Sst}=$} & 160 & \\
\hline & & & \multicolumn{7}{|c|}{ Variance of residual $(\delta o)^{2}=\mathrm{Qp} / \mathrm{Ssp}=$} & 0,001265 & \\
\hline & & & \multicolumn{7}{|c|}{ Critical tabular value Ftab at F-distribution for significance threshold $\alpha=0,01$} & 2,200 & \\
\hline
\end{tabular}


Table 2. Analysis of variance for sytethic criterion $U$ in 2466 experiment, without factor $B$

\begin{tabular}{|c|c|c|c|c|c|c|c|c|}
\hline \multicolumn{2}{|c|}{ Eksperiments UB } & \multicolumn{6}{|c|}{ Obtained results (Yijklm)Pi in repetitions $\mathbf{P i}$} & \multirow{2}{*}{$\Sigma$ Ypi } \\
\hline No. & Status & P1 & $\mathbf{P 2}$ & P3 & P4 & P5 & P6 & \\
\hline 1 & & 0,611 & 0,622 & 0,629 & 0,588 & 0,664 & 0,613 & 3,727 \\
\hline 2 & a & 0,671 & 0,700 & 0,679 & 0,625 & 0,599 & 0,607 & 3,881 \\
\hline 3 & c & 0,657 & 0,645 & 0,707 & 0,626 & 0,633 & 0,727 & 3,995 \\
\hline 4 & ac & 0,795 & 0,858 & 0,786 & 0,815 & 0,853 & 0,811 & 4,918 \\
\hline 5 & d & 0,592 & 0,672 & 0,702 & 0,622 & 0,612 & 0,626 & 3,826 \\
\hline 6 & ad & 0,653 & 0,672 & 0,743 & 0,686 & 0,711 & 0,645 & 4,110 \\
\hline 7 & $\mathrm{~cd}$ & 0,716 & 0,716 & 0,811 & 0,702 & 0,744 & 0,761 & 4,450 \\
\hline 8 & acd & 0,809 & 0,932 & 0,925 & 0,857 & 0,898 & 0,893 & 5,314 \\
\hline 9 & $\mathrm{e}$ & 0,649 & 0,692 & 0,655 & 0,708 & 0,665 & 0,680 & 4,049 \\
\hline 10 & ae & 0,699 & 0,724 & 0,725 & 0,726 & 0,778 & 0,679 & 4,331 \\
\hline 11 & ce & 0,760 & 0,770 & 0,753 & 0,797 & 0,738 & 0,787 & 4,605 \\
\hline 12 & ace & 0,913 & 0,908 & 0,915 & 0,945 & 0,925 & 0,907 & 5,513 \\
\hline 13 & de & 0,715 & 0,685 & 0,741 & 0,743 & 0,732 & 0,779 & 4,395 \\
\hline 14 & ade & 0,727 & 0,723 & 0,724 & 0,745 & 0,792 & 0,721 & 4,432 \\
\hline 15 & cde & 0,824 & 0,748 & 0,793 & 0,857 & 0,780 & 0,799 & 4,801 \\
\hline 16 & acde & 0,854 & 0,909 & 0,930 & 0,952 & 0,900 & 0,909 & 5,454 \\
\hline \multirow[t]{2}{*}{$\Sigma \mathrm{Y}^{2}$} & & 8,600 & 9,112 & 9,458 & 9,182 & 9,197 & 9,072 & \\
\hline & & & & & & & $\Sigma \mathrm{Y}$ & 71,801 \\
\hline \multicolumn{8}{|c|}{ Total sum of the square of deviation $\Sigma \mathrm{Q}=\Sigma \mathrm{Y}^{2}-(\Sigma \mathrm{Y})^{2}=$} & 0,919062 \\
\hline \multicolumn{8}{|c|}{ Corrected, explained sum of the square of deviation $\Sigma \mathrm{Qt}=$} & 0,827493 \\
\hline \multicolumn{8}{|c|}{ Unexplained residual - error $\mathrm{Qp}=\Sigma \mathrm{Q}-\Sigma \mathrm{Qt}=$} & 0,091569 \\
\hline
\end{tabular}

Table 2. Continued.

\begin{tabular}{|c|c|c|c|c|c|c|c|c|c|c|}
\hline \multirow{2}{*}{\multicolumn{2}{|c|}{ Eksperiments UB }} & \multicolumn{4}{|c|}{ Treatment combination total } & \multirow{3}{*}{ Divisor } & \multirow{3}{*}{$\begin{array}{l}\text { Effects } \\
\text { E } \\
\end{array}$} & \multirow{3}{*}{$\begin{array}{l}\text { Variance } \\
(\delta \mathrm{e})^{2}\end{array}$} & \multirow{3}{*}{$\begin{array}{l}\text { Fcal. }= \\
\delta \mathbf{e}^{2} / \delta o^{2}\end{array}$} & \multirow{3}{*}{$\begin{array}{l}\text { Signification } \\
\text { \& Rank }\end{array}$} \\
\hline & & \multirow{2}{*}{$\begin{array}{l}\mathbf{Y i + Y i + 1} \\
Y \mathbf{i}+1-Y \mathbf{i}\end{array}$} & \multirow{2}{*}{$\frac{(\mathbf{Y i}+\mathbf{Y i}+\mathbf{1})^{\prime}}{(\mathrm{Yi}+1-\mathrm{Yi})^{\prime}}$} & \multirow{2}{*}{$\frac{(\mathbf{Y i}+\mathbf{Y i}+\mathbf{1}) "}{(\mathrm{Yi}+1-\mathrm{Yi})^{\prime \prime}}$} & \multirow{2}{*}{$\begin{array}{l}(\mathbf{Y i}+\mathbf{Y i}+\mathbf{1})^{\prime \prime \prime} \\
(\mathrm{Yi}+1-\mathrm{Yi})^{\prime \prime \prime}\end{array}$} & & & & & \\
\hline No. & Status & & & & & & & & & \\
\hline 1 & & 7,608 & 16,521 & 34,221 & 71,801 & 96 & 0,74793 & & & \\
\hline 2 & a & 8,913 & 17,700 & 37,580 & 4,105 & 48 & 0,08552 & 0,175532 & 153,354 & $+\operatorname{VSSS}(2)$ \\
\hline 3 & $\mathrm{c}$ & 7,936 & 18,498 & 2,225 & 6,299 & 48 & 0,13123 & 0,413306 & 361,086 & +VSSS (1) \\
\hline 4 & ac & 9,764 & 19,082 & 1,880 & 2,591 & 48 & 0,05398 & 0,069930 & 61,095 & +SSS (4) \\
\hline 5 & $\mathrm{~d}$ & 8,380 & 1,077 & 3,133 & 1,763 & 48 & 0,03673 & 0,032377 & 28,286 & $+\mathrm{SS} \quad(5)$ \\
\hline 6 & ad & 10,118 & 1,148 & 3,166 & $-0,429$ & 48 & $-0,00894$ & 0,001917 & 1,675 & \\
\hline 7 & $\mathrm{~cd}$ & 8,827 & 1,190 & 1,349 & 0,213 & 48 & 0,00444 & 0,000473 & 0,413 & \\
\hline 8 & acd & 10,255 & 0,690 & 1,242 & $-0,199$ & 48 & $-0,00415$ & 0,000413 & 0,360 & \\
\hline 9 & e & 0,154 & 1,305 & 1,179 & 3,359 & 48 & 0,06998 & 0,117530 & 102,680 & +VSSS (3) \\
\hline 10 & ae & 0,923 & 1,828 & 0,584 & $-0,345$ & 48 & $-0,00719$ & 0,001240 & 1,083 & \\
\hline 11 & $\mathrm{ce}$ & 0,284 & 1,738 & 0,071 & 0,033 & 48 & 0,00069 & 0,000011 & 0,010 & \\
\hline 12 & ace & 0,864 & 1,428 & $-0,500$ & $-0,107$ & 48 & $-0,00223$ & 0,000119 & 0,104 & \\
\hline 13 & de & 0,282 & 0,769 & 0,523 & $-0,595$ & 48 & $-0,01240$ & 0,003688 & 3,222 & (7) \\
\hline 14 & ade & 0,908 & 0,580 & $-0,310$ & $-0,571$ & 48 & $-0,01190$ & 0,003396 & 2,967 & (8) \\
\hline 15 & cde & 0,037 & 0,626 & $-0,189$ & $-0,833$ & 48 & $-0,01735$ & 0,007228 & 6,315 & (6) \\
\hline 16 & acde & 0,653 & 0,616 & $-0,010$ & 0,179 & 48 & 0,00373 & 0,000334 & 0,292 & \\
\hline \multicolumn{11}{|c|}{$\Sigma \mathrm{Y}^{2}$} \\
\hline & & & \multicolumn{6}{|c|}{ Degree of freedom of main interaction effects, with $n=4$ factors, Sst $=2^{n}-1=$} & & 15 \\
\hline & & & \multicolumn{6}{|c|}{ Total degree of freedom, with $r=6$ repetitions, $S s u=\left(2^{n} \times r\right)-1=$} & & 95 \\
\hline & & & \multicolumn{6}{|c|}{ Degree of freedom of residual - error, $\mathrm{Ssp}=\mathrm{Ssu}-\mathrm{Sst}=$} & & 80 \\
\hline & & & \multicolumn{6}{|c|}{ Variance of residual $(\delta o)^{2}=\mathrm{Qp} / \mathrm{Ssp}=$} & & 0,001145 \\
\hline & & & \multicolumn{6}{|c|}{ Critical tabular value Ftab. at F-distribution for significance threshold $\alpha=0,01$} & & 3,000 \\
\hline
\end{tabular}


Table 3. Analysis of variance for sytethic criterion $U$ in $2^{4} x 6$ experiment with condensed factors $A$ and $C(A C)$.

\begin{tabular}{|c|c|c|c|c|c|c|c|c|}
\hline \multicolumn{2}{|c|}{ Experiments U(AC) } & \multicolumn{6}{|c|}{ Obtained results (Yijklm)Pi in repetitions $\mathbf{P i}$} & \multirow{2}{*}{$\Sigma$ Ypi } \\
\hline No. & Status & P1 & P2 & P3 & $\mathbf{P 4}$ & P5 & P6 & \\
\hline 1 & & 0,611 & 0,622 & 0,629 & 0,588 & 0,664 & 0,613 & 3,727 \\
\hline 2 & $\mathrm{~b}$ & 0,667 & 0,653 & 0,644 & 0,709 & 0,740 & 0,663 & 4,076 \\
\hline 3 & (ac) & 0,795 & 0,858 & 0,786 & 0,815 & 0,853 & 0,811 & 4,918 \\
\hline 4 & $\mathrm{~b}(\mathrm{ac})$ & 0,781 & 0,889 & 0,836 & 0,889 & 0,881 & 0,839 & 5,115 \\
\hline 5 & d & 0,592 & 0,672 & 0,702 & 0,622 & 0,612 & 0,626 & 3,826 \\
\hline 6 & bd & 0,732 & 0,742 & 0,719 & 0,770 & 0,648 & 0,735 & 4,346 \\
\hline 7 & $(\mathrm{ac}) \mathrm{d}$ & 0,809 & 0,932 & 0,925 & 0,857 & 0,898 & 0,893 & 5,314 \\
\hline 8 & $\mathrm{~b}(\mathrm{ac}) \mathrm{d}$ & 0,875 & 0,817 & 0,925 & 0,912 & 0,806 & 0,893 & 5,228 \\
\hline 9 & e & 0,649 & 0,692 & 0,655 & 0,708 & 0,665 & 0,680 & 4,049 \\
\hline 10 & be & 0,737 & 0,766 & 0,767 & 0,755 & 0,736 & 0,815 & 4,576 \\
\hline 11 & (ac)e & 0,913 & 0,908 & 0,915 & 0,945 & 0,925 & 0,907 & 5,513 \\
\hline 12 & $\mathrm{~b}(\mathrm{ac}) \mathrm{e}$ & 0,909 & 0,890 & 0,984 & 0,952 & 0,925 & 0,874 & 5,534 \\
\hline 13 & de & 0,715 & 0,685 & 0,741 & 0,743 & 0,732 & 0,779 & 4,395 \\
\hline 14 & bde & 0,781 & 0,800 & 0,809 & 0,754 & 0,731 & 0,798 & 4,673 \\
\hline 15 & (ac)de & 0,854 & 0,909 & 0,930 & 0,952 & 0,900 & 0,909 & 5,454 \\
\hline 16 & bacde & 0,939 & 0,897 & 0,942 & 0,934 & 0,896 & 0,954 & 5,562 \\
\hline \multirow[t]{2}{*}{$\Sigma \mathrm{Y}^{2}$} & & 9,723 & 10,300 & 10,627 & 10,619 & 10,121 & 10,397 & \\
\hline & & & & & & & $\Sigma \mathrm{Y}$ & 76,306 \\
\hline \multicolumn{8}{|c|}{ Total sum of the square of deviation $\Sigma \mathrm{Q}=\Sigma \mathrm{Y}^{2}-(\Sigma \mathrm{Y})^{2}=$} & 1,134822 \\
\hline \multicolumn{8}{|c|}{ Corrected, explained sum of the square of deviation $\Sigma \mathrm{Qt}=$} & 1,037565 \\
\hline \multicolumn{8}{|c|}{ Unexplained residual - error $\mathrm{Qp}=\Sigma \mathrm{Q}-\Sigma \mathrm{Qt}=$} & 0,097257 \\
\hline
\end{tabular}

Table 3. Continued.

\begin{tabular}{|c|c|c|c|c|c|c|c|c|c|c|}
\hline \multirow{2}{*}{\multicolumn{2}{|c|}{$\begin{array}{l}\text { Experiments } \\
\text { U(AC) }\end{array}$}} & \multicolumn{4}{|c|}{ Treatment combination total } & \multirow{3}{*}{ Divisor } & \multirow{3}{*}{$\begin{array}{l}\text { Effects } \\
\text { E }\end{array}$} & \multirow{3}{*}{$\begin{array}{l}\text { Variance } \\
\left(\sigma_{\mathrm{E}}\right)^{2}\end{array}$} & \multirow{3}{*}{$\begin{array}{l}\text { Fcal. }= \\
\sigma_{\mathrm{E}}{ }^{2} / \sigma_{\mathrm{o}}{ }^{2}\end{array}$} & \multirow{3}{*}{$\begin{array}{l}\text { Signification } \\
\text { \& Rank }\end{array}$} \\
\hline & & \multirow{2}{*}{$\begin{array}{l}\mathbf{Y i}+\mathbf{Y i + 1} \\
\mathrm{Yi}+1-\mathrm{Yi}\end{array}$} & \multirow{2}{*}{$\frac{(\mathbf{Y i}+\mathbf{Y i}+\mathbf{1})^{\prime}}{(\mathrm{Yi}+1-\mathrm{Yi})^{\prime}}$} & \multirow{2}{*}{$\frac{(\mathbf{Y i}+\mathbf{Y i}+\mathbf{1}) "}{(\mathrm{Yi}+1-\mathrm{Yi}) "}$} & \multirow{2}{*}{$\frac{(\mathbf{Y i}+\mathbf{Y i}+\mathbf{1})^{\prime \prime \prime}}{(\mathrm{Yi}+1-\mathrm{Yi}))^{\prime \prime \prime}}$} & & & & & \\
\hline No. & Status & & & & & & & & & \\
\hline 1 & & 7,803 & 17,836 & 36,550 & 76,306 & 96 & 0,79485 & & & \\
\hline 2 & $\mathrm{~b}$ & 10,033 & 18,714 & 39,756 & 1,914 & 48 & 0,03988 & 0,038160 & 31,389 & $+\mathrm{SS}(3)$ \\
\hline 3 & (ac) & 8,172 & 19,672 & 0,980 & 8,970 & 48 & 0,18688 & 0,838134 & 689,418 & $+\operatorname{VSSS}(1)$ \\
\hline 4 & $\mathrm{~b}(\mathrm{ac})$ & 10,542 & 20,084 & 0,934 & $-1,434$ & 48 & $-0,02988$ & 0,021420 & 17,620 & -SS (4) \\
\hline 5 & d & 8,625 & 0,546 & 4,600 & 1,290 & 48 & 0,02687 & 0,017334 & 14,259 & $+\mathrm{S}(5)$ \\
\hline 6 & bd & 11,047 & 0,434 & 4,370 & $-0,274$ & 48 & $-0,00571$ & 0,000782 & 0,643 & \\
\hline 7 & (ac)d & 9,068 & 0,548 & $-0,758$ & $-0,334$ & 48 & $-0,00696$ & 0,001162 & 0,956 & \\
\hline 8 & $\mathrm{~b}(\mathrm{ac}) \mathrm{d}$ & 11,016 & 0,386 & $-0,676$ & $-0,118$ & 48 & $-0,00246$ & 0,000145 & 0,119 & \\
\hline 9 & e & 0,349 & 2,230 & 0,878 & 3,206 & 48 & 0,06679 & 0,107067 & 88,069 & +SSS (2) \\
\hline 10 & be & 0,197 & 2,370 & 0,412 & $-0,046$ & 48 & $-0,00096$ & 0,000022 & 0,018 & \\
\hline 11 & (ac)e & 0,520 & 2,422 & $-0,112$ & $-0,230$ & 48 & $-0,00479$ & 0,000551 & 0,453 & \\
\hline 12 & $\mathrm{~b}(\mathrm{ac}) \mathrm{e}$ & $-0,086$ & 1,948 & $-0,162$ & 0,082 & 48 & 0,00171 & 0,000070 & 0,058 & \\
\hline 13 & de & 0,527 & $-0,152$ & 0,140 & $-0,466$ & 48 & $-0,00971$ & 0,002262 & 1,861 & \\
\hline 14 & bde & 0,021 & $-0,606$ & $-0,474$ & $-0,050$ & 48 & $-0,00104$ & 0,000026 & 0,021 & \\
\hline 15 & (ac)de & 0,278 & $-0,506$ & $-0,454$ & $-0,614$ & 48 & $-0,01279$ & 0,003927 & 3,230 & $-S(7)$ \\
\hline 16 & bacde & 0,108 & $-0,170$ & 0,336 & 0,790 & 48 & 0,01646 & 0,006501 & 5,348 & $+\mathrm{S}(6)$ \\
\hline \multicolumn{11}{|l|}{$\Sigma \mathrm{Y}^{2}$} \\
\hline & & & \multirow{2}{*}{\multicolumn{6}{|c|}{$\begin{array}{l}\text { Degree of freedom of main interaction effects, with } \mathrm{n}=4 \text { factors, } \mathrm{Sst}=2^{\mathrm{n}}-1= \\
\text { Total degree of freedom, with } \mathrm{r}=6 \text { repetitions, } \mathrm{Ssu}=\left(2^{\mathrm{n}} \times \mathrm{r}\right)-1=\end{array}$}} & & 15 \\
\hline & & & & & & & & & & 95 \\
\hline & & & \multicolumn{6}{|c|}{ Degree of freedom of residual - error, Ssp $=$ Ssu - Sst $=$} & & 80 \\
\hline & & & \multicolumn{6}{|c|}{ Variance of residual $\left(\sigma_{\mathrm{o}}\right)^{2}=\mathrm{Qp} / \mathrm{Ssp}=$} & & 0,001216 \\
\hline & & & \multicolumn{6}{|c|}{ Critical tabular value Ftab. at F-distribution for significance threshold $\alpha=0,01$} & & 3,000 \\
\hline
\end{tabular}

4. Periodical plan and report - the first higher planning period, covering 2-6 months

5. Basic plan and the report - the basic planning period, covering 15 days to 3 months

6 . Timing schedule and report - the first lower planning period, covering 7-30 days
7. Detailed plan and report - the second lower planning period, covering 1-7 days.

It is certainly possible to choose in some concrete production systems some other variants of the basic planning period, and thus also dynamics of flexibility that does not essentially have to be at equal time intervals. However, one 
shoud seek an objective compromise between the stability of the production process and adaptability of the production system to changes in the environment.

In any case, when making decisions on the selection of model of flexible operational planning and production control and its intensity for the treated production system, it is necessary to consider in detail the functional relations between all direct processes related to operational planning and production control, according to expression (7)

$$
\mathrm{IPP}=\mathrm{f}(\mathrm{Ppr}, \mathrm{Pp}, \mathrm{Pn}, \mathrm{Ppp})
$$

where: IPP - intensity of operational planning and production control

Ppr - reliability of production (machines, executives, subcontractors, etc)

$\mathrm{Pp}$ - reliability of sales (knowledge of the sales market by quantities and terms)

Pn - reliability of supply (knowledge of the supply market by quantities and terms)

Ppp - reliability of operational planning and production control (knowledge, techniques, tools, risk control)

In view of dynamic changes in time, some of the dynamic programming mathematical models should be surely used in the process of operational planning and production control, because the time is a factor important in the operational planning and production control issues.

This suggests the need to create a model that will, through some mathematical programming methods and techniques, define optimal plans for a particular time period on one hand, and will also most appropriately react to important changes and disturbances that can occur at any particular time and can significantly affect the pre-set solutions.

In case the dynamic programming model includes the optimal way of solving the situations of changes and disturbances in particular parts of the period for which the most favourable solution has been previously given, it is possible to proceed in one of the following 2 ways:

Treat again the selected planning period from the moment of decision making about the same

Define by simulation a solution for the correction of the existing plan

It is to be expected that by applying method in A. it would be necessary to make a lot of changes in the existing plans, and it is therefore far more efficient to make corrections in the way presented in B., i.e. by applying simulation method.

In that case it is necessary to find the optimum of the corrected basic plan as part of the first higher plan defined by dynamic programming. This means that by applying the simulation method the correction of the basic plan is periodically done by maximizing the function $\Phi^{\prime}=\Phi^{\prime}$ (U1) and it is done so for any subsequent basic planning period (U2, U3, . Ui).

\section{Conclusion}

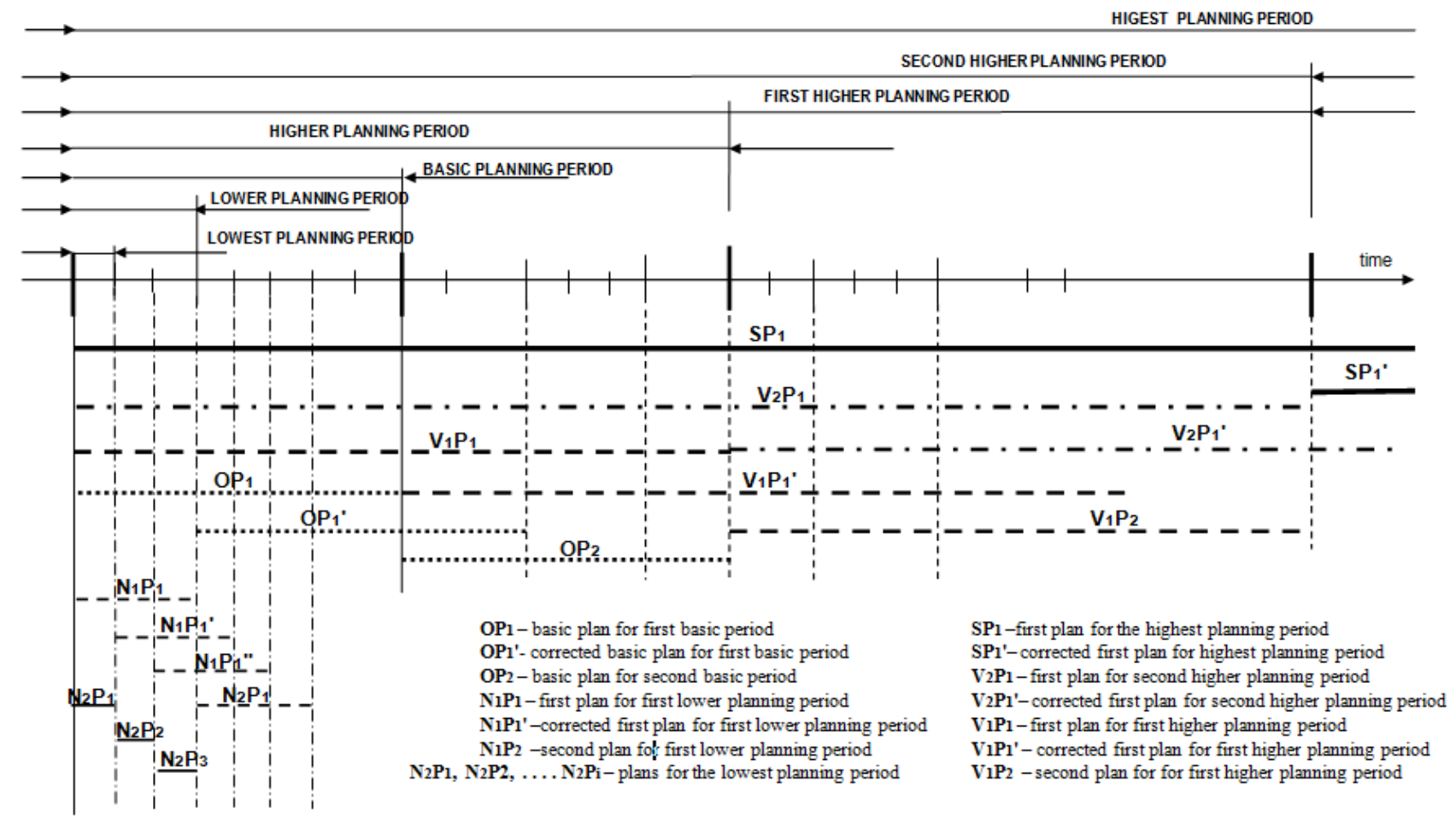

Figure 2. General schematic presentation of flexible planning and control.

A goal-oriented, dynamic and well organized process of operational planning and production control starts from the fact that today in an environment full of sudden, great and numerous unexpected changes the aim is not to optimize the state of an enterprise-system in terms of gain or profit only. Also, the aim is to optimize the adaptibility and flexibility as indicators of its dynamic optimization of work and business operation, whereat the minimum costs and realization time 
are taken as criteria.

It could be said that the goal of operational planning and production control is to find solutions for maximal meeting of the market needs through the realization in production, having at the same time the maximum possible business success of an enterprise and its adaptability to changes in the environment and in the production system itself.

Only a constant link with the systems and processes in the environment with which a considered system is connected, a continuous dynamic adjustment to the needs of the environment-market, and a steady, intense collaboration between all parts of the considered system-enterprise enable its existence and development, whereat most of these activities take place within the process of operational planning and control.

In this sense, operational planning and control is not only important and influential for production, as it is usually considered, but has a much more complex task. This presupposes continuous connection - through appropriate activities - of methods and work techniques that are used for continuous linking of contents from the environment-market, production, logistic-supporting events and parameters into a coherent, optimal unit and results.

Therefore, it is difficult to provide unified, common solutions for operational planning and production control, because each system is specific with respect to its structure, processes and people, and changes in the environment have different effects on different systems, especially from the aspect of time.

A possible general solution would be the development and establishment of an appropriate simulation model for adopting certain decisions and solutions in advance, prior to application in the working processes of a system. This also requires intensive planning, control and management of all activities in the process of operational planning and control, and especially those that are related with other processes of the system, such as corrective dynamic optimization.

\section{References}

[1] T.J.Coelli; D.S. Prasada Rao; C.J. O'Donnell; G.E.Battese, "An Introduction to Efficiency and Productivity Analysis", 2. edition, Springer, NewYork, 2005.

[2] T.E.Vollman; W.L.Berry; D.C.Whybark, "Manufacturing Planning And Control System", 4. edition, McGrow-Hill, 1997.

[3] T. C. Miller, "Hierarchical Operations And Supply Chain Planning", Springer, New York, 2002.

[4] M. L. Pinedo, "Planning and Scheduling In Manufacturing and Services", Springer, New York, 2004.
[5] S. T. Hackman, "Production Economics", Krieger Publishing Co., Melbourne, Florida/US, 2007.

[6] M. Caramia; P. Dell' Olmo, "Effective Resource Management in Manufacturing Systems: Optimization Algorithms for Production Planning", Springer, New York, 2006.

[7] S. Voss; D. L. Woodruff; "Introduction To Computational Optimization Models For Production Planning In A Supply Chain", Springer, New York, 2002.

[8] P. Argonato \& Coautors, "Production Planning In Production Networks: Models For Medium and Short-term Planning", Springer, New York, 2008.

[9] L.C.Hendry; B.G.Kingsman, "Production Planning System and Their Applicability to Make-to-order Companies", European Journal of Operational Research, Vol.40, pages 1-15, 1989.

[10] N.Štefanić; N.Gjeldim; T.Mikac, "Primjena Lean koncepta u proizvodnoj djelatnosti", Tehnički vjesnik, br.17 (3) stranice 353-356, 2010.

[11] J. J. Kanet; Martin Stoesslein, "Integrating Production Planning And Control: Towards A Simple Model For Capacitated ERP", Production Planning \& Control Journal, 3/2010, pages 286-300.

[12] D. Aprile, A. C. Garavelli, I. Giannoccaro, "Operations Planning and Flexibility in a Supply Chain", Production Planning \& Control Journal, 1/2005, pages 21-31.

[13] J. N. D. Gupta, "An Excursion in Scheduling Theory: An Overwiew of Scheduling Research in the Twentieth Century", Production Planning \& Control Journal, 2/2002, pages 105116.

[14] G. Xue, O. F. Offodile, H. Zhou, M. D. Troutt, " Integrated Production Planning with Sequence-dependent Family Setup Times", International Journal Of Production Economics, Vol.131/2011, pages 674-681.

[15] J. Mula, R. Poler, J. P. García-Sabater, F.C. Lario, " Models for Production Planning under Uncertainty: A Review", International Journal Of Production Economics, Vol.103/2006, pages 271-285.

[16] T. Volling; T. S. Spengler, "Modeling and Simulation of Order-driven Planning Policies in Build-to-order Automobile Production", International Journal Of Production Economics, Vol.131/2011, pages 183-193.

[17] J. J. Kanet; M. Stoesslein, "Integrating Production Planning And Control: Towards A Simple Model For Capacitated ERP", Production Planning \& Control Journal, 3/2010, pages 286300.

[18] B. Gordic, " A Contribution to the Determination of Criteria and Measures For Evaluating Operational Planning and Production Control", Technical Gazette, Vol. 18/2011, pages 109-115. 